\title{
THE EFFECT OF TOURISM OVERNIGHT STAYS ON CROATIA'S EXTRA VIRGIN OLIVE OIL PRICES AND MARKET POWER: AN EMPIRICAL STUDY
}

\author{
Zdravko Šergo " *, Jasmina Gržinić ${ }^{2}$ and Anita Silvana llak Peršurić ${ }^{1}$ \\ ${ }^{1}$ Institut of Agriculture and Tourism \\ Poreč, Croatia \\ 2Juraj Dobrila University in Pula - Faculty of Economics and Tourism 'Dr.Mijo Mirković' \\ Pula, Croatia \\ DOI: $10.7906 /$ indecs.19.4.6 \\ Regular article \\ Received: 11 February 2021. \\ Accepted: 16 November 2021.
}

\begin{abstract}
The objective of this study was to analyse the impact of positive externalities of international tourism demand on increasing the market power (MP) of an extra virgin olive oil (EVOO) wholesaler in Croatia. In the context of this article, the MP measures how close the wholesaler can set the actual price of EVOO to the maximum the retailer wants to pay. Our hypothesis explained how the additional demand of tourist consumers for EVOO could stimulate and increase the MP of the wholesalers. Here, it was important to remember that the EVOO market signals relatively asymmetric quality information about products that varies in certain ranges. The selected time-series span the weekly period from 2017 to 2019. We used the Toda-Yamamoto approaches of causality in the relationship between the EVOO price gap and tourism overnights, as well as the autoregressive distributed lag model (ARDL) bounds test for cointegration. For larger EVOO bottles $(0,751$ and 11$)$, there is unidirectional causality flowing from tourism consumption, which we presume originates from the tourism demand variable, to MP. There is a relevant bidirectional causality in the case of the 0,251 bottle. Tourism in a purchased bottle of 0,5 1 does not manifest any side-effect impact on MP. This pioneering study has investigated the relationship between the MP of EVOO wholesalers in Croatia and tourist demand. An inventive view has been adopted with regard to the theoretical concept of measuring MP, but also due to the steps towards the use of ARDL bound testing.
\end{abstract}

\section{KEY WORDS}

extra virgin olive oil, market power, tourism, ARDL model, Toda-Yamamoto causality

\section{CLASSIFICATION}

JEL: D49, Q13, Z33 


\section{INTRODUCTION}

This article investigates the MP of EVOO, which in our opinion is associated with rising international tourist demand, at least until the Covid-19 pandemic, using the example of the Republic of Croatia's wholesale trade. We argue that purchasing power is enriched by tourist buyers, which in turn causes EVOO price rises, empowering wholesalers' position in the supply chain. International tourist demand has recorded high growth rates in recent years, which has increased the consumer potential for buying bottled EVOO in Croatia. Using the positive externalities, our hypothesis asserts that tourist consumers cause an increased MP for wholesalers.

The research on market power (MP) in the olive oil trade is relatively scarce and it is mostly centred on exports [1,2]. Before exploring the connections between MP and the growth in tourism, in order to justify researching the topic in that direction, we should state that the MP of wholesalers has grown generally because of their sizes, economics of scale, and organisational advantage. Wholesale provides a genuine economic function in the European economy; from a value chain perspective, it is an input to almost all production processes (the highest share of wholesale inputs had found in food and beverages and the lowest in construction, see in [3]). The rise of wholesalers has been driven by an intuitive complementarity between their sourcing of goods from abroad and an expansion of their domestic distribution network to reach more buyers. Both elements require scale economies and lead to increased wholesaler market shares and markups, as explained in [4].

During the past two decades, Croatia has experienced rapid growth and the spread of supermarket chains; moreover, the number of shelves in tourist centres has multiplied. Several factors account for this spread of shelves along with the occurrences of new trade counters, including the penetration of international supermarkets (Lidl, Kaufland, Spar, etc.) in Croatia seeking for a new profit source, greater economies of scale and scope, and more efficient procurement and distribution systems. Furthermore, the country's well-development tourism industry, EU membership, and expected increasing per capita income have encouraged a new demand potential for EVOO products, which influenced in engrossing supermarkets.

Due to increased costs and safety risks associated with losses, family olive planters (although this topic is out of the focus of this article) have been coerced to deliver produced EVOO to the wholesaler rather than leaving store surpluses unsold.

The wholesaler, in the oligopoly market structure, poses the strong potential for double marginalisation (both stages mark up prices above marginal cost) and its associated inefficiencies (double deadweight losses), as well as the potential effect on price transmission throughout the chain at the horizontal structure level, i.e. from the food processing stage to the retailing stage [5]. The modern distribution channels (hypermarkets, supermarkets and discount stores) and their prices are major final absorbers of these EVOO prices, which buyers accept (or become the default due to boycotting).

Tourist buyers may distort extra-market sources of information about EVOO reputations, and it is very rare that there is repeated trade that serves a correctional purpose. This is especially the case when EVOO with a falsified declaration of content quality is involved. The analysis of Croatia's IPTPO panellists, the internationally recognised olive oil tasters in the county among the very few, indicate that one in three oils chosen randomly does not correspond to the category of EVOO; also according to [6] most of the imported oils from abroad do not meet the quality which is declared on the labels of EVOO bottle.

In relatively unknown products, such is exotic EVOO bottled in a small volume with a decent design, functions as a souvenir as opposed to a grocery item; that items may not ever signal required quality via the price level. 
Food souvenirs are tangible reminders of a travel destination and play an important role in the hospitality and tourism industry [7]. Bottled EVOO as a souvenir is often a mandatory purchase guided by an instinct desire to possess a suitable symbol of a meagre but above all healthy Mediterranean diet. In this context, the organoleptic quality does not have to be commensurate with the price. Under such circumstances, the utility function can be non-negative for a specific price range and generate an inverted U-shaped function. According to [8], the EVOO market in Chile is a good example. Therefore, minimal and maximal prices can significantly deviate, hitting consumer surplus. Consumer knowledge of this product, we argue in this article is still limited, especially for foreign, myopic, and naïve tourist consumers.

In this article, we also argue that in circumstances of asymmetric information communication, 'money for value' or EVOO prices may vary in ranges. That range constructs an imaginary price gap for which the trajectory can deviate from the average price, which may in turn anticipate the wholesaler MP. In this article, the model will be put to the test for the very first time the hypothesis that demand generated by tourism has significantly stimulated the widening price gap in EVOOS trading, driving the MP of wholesalers higher and higher.

Therefore, we have given serious attention to the 'tourism and MP effect' nexus which affects demand for the bottled EVOO market. To that end, we have used a different approach to investigate the relationship among olive oil MP and tourism growth, namely an ARDL cointegration test developed by [9-10], as well as the specific technique of causality analysis given in [11], based on weekly data for the period between 2017 and 2019. This recent three-year period has been chosen because these have been the most prosperous years in terms of Croatia's tourism industry development.

Modelling the relationship function between the MP of EVOO from a wholesaler perspective and tourism demand is an important area of research. The price gap, i.e. differential prices for EVOO, will be instrumented in our objective to deliver the impact of international tourism overnight stays on MP. The rest of this article is organised as follows: in Section 2 provides a short literature review; Section 3 explains the theory and general model and constructs the estimation procedure (including the unit root test, the ARDL approach and Toda-Yamamoto causality analysis), as well as providing the data; Section 4 explains the empirical results; and, finally, Section 5 offers concluding remarks and outlines the policy implications.

\section{LITERATURE REVIEW}

The subject of MP in the olive oil trade has not been studied extensively, at least according to academic articles composed in the past. A comparative analysis of the MP of olive oil exporting countries indicates that exports are imperfectly competitive in the EU market, and that Italy has higher MP compared to Spain and Greece [2]. Other authors reached a similar finding as far as Italy is concerned while Tunisia has the lowest MP in relative terms [1]. Both articles place the research problem in the environment of economic comparative studies of the Mediterranean countries, using the same method to measure the exporter's MP, as in [12].

In papers written by other authors, there is an assumption that olive oil tourism based on a typical gastronomic product of internationally recognised quality boosts sustainable destination development [13]. Oleotourism, or olive oil tourism, is a practice that contributes to highlighting an emblematic resource for Europe, with a special emphasis on the countries of the Mediterranean basin, receiving the mayor number of consumers interested in this type of resource [14]. Links between the tourism demand and olive oil supply, in various perspective are brought to light in manny papers [15-19]. Some authors, like [20] have emphasised that the 
price of EVOO is highly subject to variability, meaning the consumer is not able to perceive a price of reference. In a study addressing consumer misuse of country-of-origin labels conducted in Italy, the authors test whether there is a price differential associated with the country-of-origin information for EVOO [21]. As a high value commodity on the market, EVOO is a suitable target for fraudsters [22]. To address whether there is a relationship between the value of attributes based on the market price and on consumer utilities a hedonic price (HP) approach is combined with the actual consumer utilities from a real choice experiment (RCE) for EVOO attributes in a study produced by [23]. Various tastes and preferences, demand and supply, the rental position of stores, and other complexities dictate the range of price heterogeneities for the homogenous product, accentuating standard consumer theory. Furthermore, search frictions resulting from agents' imperfect information about sellers' prices explain the price dispersion in otherwise homogeneous product markets [24]. Other authors underline that the olive-oil based tourism loses momentum in a rural destinations, since many cultural cities are offering tourism experiences focused on highlighting the cultural and sensory content of gastronomy and typical productions such as EVOO [25-27].

\section{THEORY, METHODOLOGY AND DATA}

\section{THEORY}

The literature suggests a considerable range of MP measures based on industry concentration measures, entry barriers, and various indexes (for more one can see [28]). We will not consider the theoretical underpinning in that direction because we are dealing with a homogenous product based emerging MP rather than a firm or a sector. Otherwise, profitability data or EVOO returns is unfortunately lacking.

Our theoretical consideration is based on [29], which tells that MP and a large markup arise because there is a product (in our case EVOO) that customers happen to enjoy and are willing to pay a premium to obtain. The retailor, we assume, buys EVOO at storage from the wholesaler agent, with whom they communicate on a regular basis. There is a maximum price that the retailer will pay for bottled EVOO from the wholesaler, and that price depends on the quality of the oil itself, the convenience of the store location, and how pleasant his or her staff are to the final customers. If the retailor strategically does business with zero profit margin, minimum prices will be a frequent attractor to that store. The actual price that the retailor pays lies somewhere between those two. In the opposite case, one of the two subjects (retailor or wholesaler) would refuse to participate in the transaction of traded EVOO. Further, if we transpose a previous theoretical story on the wholesaler perspective, we have to turn the situation upside-down.

The consequence of this mental exercise provides us with the metrics of MP. However, there is a different way to conceive of and measure the MP of EVOO on wholesaler grounds. Rather than focusing on total economic profits from EVOO trafficking (as stated previously, that micro-segmented panel data is unfortunately unavailable), we could instead focus on the extreme price poles (maximum and minimum) considering that the minimum price is approximately equivalent to the value charged by wholesalers relative to their costs.

The MP of wholesalers is therefore a measure of how close the wholesaler agent can set the actual price up to the maximum according to which that agent will sell considering the operating cost. The marginal cost per item in this case is the actual price paid to the lowest price a wholesaler will accept. Therefore, even if we do not know the profits that wholesalers receive in such exchanges, we can measure the MP. The larger the trade, the more abnormal 
the return yielded by the MP. This might be supported by asymmetric information communication between the tourist customer and the retailor.

We assumed that the swollen demand for EVOO due to increased overnight tourist stays in recent years has positively affected the growth of the MP for wholesalers.

The set general theoretical model depicts the narrative connection, and this is followed by the empirical verification.

$$
\mathrm{MP}=\mathrm{f}(+\mathrm{NIGHT}),
$$

where MP is as we suggested, streamlining, ground on the differential between maximal price and minimal price; that gap is a proxy for the MP and NIGHT represents international overnight stays, which on the other hand is a proxy for international tourism demand.

Such a formulation is in line with the aforementioned general consideration regarding the link between overnight tourist stays and the MP in the oil wholesaler's market consideration.

Accordingly, the main hypothesis of this study is as follows: an increase in overnight stays involving international tourists boosts the MP of EVOO from a wholesaler perspective.

\section{ECONOMETRIC METHODOLOGY}

\section{ARDL cointegration and bounds tests}

To analyse the long-term relationship between a set of variables, authors [10] suggested the use of an autoregressive distributed lag procedure or bounds test that does not require stationary pre-testing, and which can be used regardless of whether the variables are I(0), I(1), or mutually cointegrated, given that none of the series is $\mathrm{I}(2)$. Despite these relaxing circumstances, we have produced a verification to determine whether second-order integration in some time series exists by conducting a ADF and DF-GLS unit root test in order to eliminate further exercises with data that encompass some of the variables. It is highly probable that the results will direct us to employ an ARDL bound test [10]. Therefore, if those tests show that the individual time series variable is either I(0) or I(1), an analysis with that price of EVOO will continue with the bounds test. The ARDL model has a certain number of advantages over traditional methods of testing cointegration. Firstly, as specified before, this method puts less strain on unit-root testing. Secondly, we can simultaneously estimate the short-run as well as long-run relationship among the variables using the ARDL bound testing procedure. Our sample has 156 weekly observations; the characteristics of long-term regressed series do not lose significance due to a considerable amount of high-frequency data. In addition, the ARDL model takes care of endogeneity issues by adding lags for both dependent and independent variables in the model. Finally, the ARDL model can be converted into a twin unrestricted error correction model (UECM), including both short-run and long-run dynamics. The bounds test is based on the following UECM:

$$
\Delta Y_{t}=\text { const }+\Sigma \beta \Delta Y_{t-1} k_{i}=1+\Sigma \gamma \Delta X_{t-1} k_{i}=1+\omega Y_{t-1}+\theta X_{t-1}+\varepsilon_{t},
$$

where $Y_{\mathrm{t}}$ denotes price gap measured in EVOO and $X_{\mathrm{t}}$ denotes a tourist overnight stay as a single input (as explained previously), both expressed in natural logarithms. An appropriate lag selection is based on the Schwarz Bayesian Criterion (SBC). The automated model selection process involves choosing the maximum lag for each regressor, which is set as 8 (because the data is weekly). The ARDL procedure allows for the possibility that the variables may have different optimal lags (after the searching process has ended), whereas this is impossible with 
conventional cointegration procedures. The null hypothesis for no long-term relationship between the price gap and the tourism input variable is not rejected, by testing the $F$-statistic, when:

$H_{0}: \omega=\theta=0$,

against the alternative

$H_{0}: \omega \neq \theta \neq 0$.

Instead of the conventional critical values, authors [10] proposed a bounds test for two sets of critical variables. The first set assumes that all variables are (0), and the other set assumes that all variables are (1). If the tested $F$-statistic (or Wald statistic) value lies below the lower bound critical value, then the null hypothesis of a non-existent cointegration relationship cannot be rejected; further, if it exceeds the respective upper bound critical value, the null hypothesis is rejected. If the tested $F$-statistic value falls within the lower and upper critical value bounds, inference is inconclusive. Furthermore, because of the potential existence of a trend in the series (if the former case is unable to identify cointegration between two series), estimations are completed to satisfy the unrestricted intercept and no trend case (as an auxiliary test). Model diagnostic checking is particularly significant in the sense that some important ARDL assumptions such as errors are serially independent and normally distributed. Estimations are completed using an ordinary least squares procedure alongside the White's test for cross-sectional heteroscedasticity-consistent standard errors, as well as a covariance matrix, appropriate serial correlation diagnostics (the Breusch-Godfrey LM test), and the Jarque-Bera statistic for the normality test. The graphical recursive CUSUM and moving sum (MOSUM) of the recursive residuals according to [30, 31] are applied to detect whether any autoregressive structure is integrated into the model. These tests have been employed to assess the parameter stability of the model.

\section{Causality analysis}

The initiation of proceedings within Toda-Yamamoto causality analysis occurs if the cointegration link between MP and NIGHT persists. Formally speaking, if a price gap and an international tourist overnight input as a metric of consumption are regressed against one another in levels, the resulting residuals essentially represent error correction terms. These terms measure deviations in the long-run equilibrium between the two series. Hence, the ARDL (1) can be re-parameterised after replacing $Y_{\mathrm{t}-1}$ and $X_{\mathrm{t}-1}$ with the lagged residuals:

$$
\Delta Y_{t}=\text { const }+\alpha \mathrm{ECT}_{\mathrm{t}-1} \cdot \sum_{\mathrm{i}=1}{ }^{\mathrm{n}} \rho \Delta Y_{t-1}+\sum_{\mathrm{i}=1}{ }^{\mathrm{p}} \sigma \Delta X_{t-1}+\mu_{\mathrm{t}},
$$

e.g., the error correction model via the two-step procedure of Engle and Granger.

These lagged residuals represent an error correction term, denoted in this article by $\mathrm{ECT}_{\mathrm{t}-1}$, which provides an insight into the speed of adjustment to a long-run equilibrium within a particular time frame from a change to one of the series. Furthermore, if the coefficient of $\mathrm{ECT}_{\mathrm{t}-1}$ is statistically significant (by $\mathrm{t}$-value), long-run causality is confirmed. $\mathrm{ECT}_{\mathrm{t}-1}$ should be between 0 and 1 with a negative sign, which implies convergence of the system back to the long-run equilibrium position.

Additionally, the direction of cause and effect between the variables - testing the hypothesis that tourist demand measured by the number of overnight stays causes an increase in the MP of EVOO wholesalers - will be clarified by using the Modified Wald test (MWALD) recycled according to the Toda-Yamamoto (1995) procedure. The MWALD test skips obstacles and problems associated with the classic Granger causality test resulting from non-stationarity or cointegration between series. It is to be expected that the latter problems would cause a theoretical inconsistency in collision with the empirical performance of the classical Granger 
causality test [32-34]. Unlike the Granger causality test, the Toda-Yamamoto (1995) causality test is performed using a standard VAR model in levels rather than first differences; this process minimise the risk of misidentifying the order of integration [35].

To apply the Toda-Yamamoto [11] version of the Granger non-causality test, we summarise the MP-NIGHT model in the following VAR system:

$$
\begin{gathered}
M P_{t}=\alpha_{0}+\sum_{i=1}^{k} \alpha_{1 i} M P_{t-1}+\sum_{i=1}^{d \max } \alpha_{2 j} M P_{t-j}+\sum_{i=1}^{k} \delta_{1 i} N I G H T_{t-1}+\sum_{i=1}^{d \max } \delta_{2 j} N I G H T_{t-j}+\gamma_{1 t}, \\
N I G H T_{t}=\beta_{0}+\sum_{i=1}^{k} \beta_{1 i} N I G H T_{t-1}+\sum_{i=1}^{d \max } \beta_{2 j} N I G H T_{t-j}+\sum_{i=1}^{k} \eta_{1 i} M P_{t-1}+\sum_{i=1}^{d m a x} \eta_{2 j} M P_{t-j}+\gamma_{2 t} .
\end{gathered}
$$

From (3), the Granger causality from NIGHT to $\mathrm{MP}_{\mathrm{t}}$ implies $\delta_{1 \mathrm{i}} \neq 0$ for all $\mathrm{i}$; similarly, in (4), $\mathrm{MP}_{\mathrm{t}}$ Granger-causes NIGHT $_{t}$ if $\eta_{1 i} \neq 0$ for all $\mathrm{i}$. The bi-variable model is estimated using seemingly unrelated regression (SUR), as in [35].

\section{ABOUT THE DATA}

In order to examine the relationship among the variables, the study used weekly time-series data from 2017-2019 for four different volumes of bottled EVOO. In this study, the MP proxied by price gap is the dependent variable. Tourism demand is proxied by overnight stays (NIGHT), and this is the only variable singled out as the independent variable. MP in our reconsidered theory of price differential variability provides the basis for its dynamic measurement. The MP marked with different volume labels - detailed later in the text - will distinguish various prices per volume: 0,25 litres, 0,5 litres, 0,75 litres, and 1 litre. Auxiliary variables (maximal and minimal prices) for calculation of MP were sourced from an overview of wholesale EVOO prices by week given in Kn per litre, given in [36].

International tourism overnight stays (NIGHT) sourced from Eurostat [37] are used as a measure of tourist demand, and in this study have been used as an alternative (substitutive term) to tourism consumption given that this could not be deduced from the Eurostat website on a weekly frequency. This procedure has been undertaken to match the same data consistently with the MP time series variable.

A few extra words would be good to mention here, in this data section.

The tourism overnight time series data is unfortunately in the form of quarterlies. Because of the ARDL time series methodology, the postulated requirement of designed studies is a disaggregation of their lower-frequency value to higher (or weekly unit) values. The tourism overnight stays data and the inherited seasonality in that data has enabled us to obtain weekly tourism overnight stays entries with a prudent time span length (2017week1-2019Qweek52) through temporal desegregation techniques, as explained by Chow-Lin (for more, see in [38]). All the variables used in this article come in their natural log form.

The data series for the selected economies contains 156 weeks. Hence, we suppose that idiosyncratic outliers and structural breaks may be hidden in the Data Generating Process (DGP) of our weekly time series. As pointed out above, an adequate technique to handle these handicaps is the ARDL bounds test approach.

\section{EMPIRICAL RESULTS}

\section{UNIT ROOT TEST}

Before conducting tests for cointegration, it is vital to ensure that the variables under consideration have not been integrated at an order higher than 1 . In the presence of I(2) or higher variables, the computed statistics provided by authors [10, 39] are not valid according to [40]. Thus, in order to establish the integration properties of the series, we used quick ADF 
and DF-GSL unit root tests to confirm that none of the series was I(2). Accordingly, both tests were at level and at first difference (if the level test was non-stationary), and the results are shown in Table 1.

Table 1. Unit root test (ADF and DF-GLS) test.

\begin{tabular}{|l|c|c|c|}
\hline & \multicolumn{2}{|c|}{ Augmented Dickey-Fuller Test } & DF-GSL \\
\hline Levels & MP1 & $-11,800(0)^{* * *}$ & $-4,022(1)^{* *}$ \\
\hline First difference & & - & - \\
\hline Levels & MP075 & $-7,298(1)^{* * *}$ & $-7,185(1)^{* * *}$ \\
\hline First difference & & - & - \\
\hline Levels & MP05 & $-3,642(3)^{* * *}$ & $-4,413(2)^{* * *}$ \\
\hline First difference & & - & - \\
\hline Levels & MP025 & $-5,480(2)^{* * *}$ & $-7,068(1)^{* * *}$ \\
\hline First difference & & - & - \\
\hline Levels & NIGHT & $-2,511(4)$ & $-2,912(1)^{*}$ \\
\hline First difference & & $-4,988(4)^{* * *}$ & $-5,021(3)^{* * *}$ \\
\hline
\end{tabular}

Note: all the regressions include a linear trend in the levels and include an intercept in the first differences.

Note: the numbers in parentheses are the optimal lag orders and are selected based on Schwarz Bayesian.

Note: the DF-GLS test statistics include an intercept and a linear time trend in the levels and only an intercept in first difference [41].

*significant at level $1 \%$,

*** significant at the level $5 \%$

*** significant at the level $10 \%$

As indicated in Table 1, the ADF and DF-GLS tests reject the null hypothesis of the unit root at levels for MP variables in the full spectrum, implying that the dependent variables are stationary at levels. Nonetheless, regarding the independent NIGHT variable, we do not accept the $10 \%$ significance. The null hypothesis is however rejected at the $1 \%$ significance level, at the first difference, implying that the NIGHT variables become stationary at the first difference. In our case, we have a mix of I(0) and I(1) variables. Therefore, we can apply the tests proposed by authors [10] and proceed with the test for cointegration.

\section{RESULTS OF THE ARDL COINTEGRATION TESTS}

In the first step in applying the bounds test, we specified the optimal lag length of the UECM, i.e., Equation (1), and checked the long-run level equilibrium relationship.

We have attempted to optimally set up the ARDL model and fixed an optimal lag, which is crucial. With an initial lag of 8, the automated model selection, according to minimal SBC [9], calculates the optimal lag length. The results of the cointegration test using ARDL are presented in Table 2. The estimated ARDL model has passed several diagnostic tests, meaning there is no evidence of serial correlation, heteroscedasticity, or deviation from normal distribution. The cumulative sum of the CUSUM and moving sum (MOSUM) for the recursive residuals plots - which is shown in Figure 1-4 from a recursive estimation of the model - also indicate stability in the coefficients over the sample period in all cases (in Appendix). This indicates that the model is well founded and suitable for the study of cointegration among the variables.

The F-statistics for cointegration analysis based on the selected ARDL models are reported in Table 2 for all EVOO price gap cases. All the reported F-statistics - as well as the t-statistics - lie above the upper bounds; consequently, the null hypothesis of no cointegration is rejected and the precondition for cointegration is established in all four EVOO volumes. 
Table 2. Result of the cointegration test using ARDL Approach (case III).

\begin{tabular}{|c|c|c|c|c|c|c|c|}
\hline $\begin{array}{c}\text { Dep. } \\
\text { variable }\end{array}$ & $\begin{array}{c}\text { Indep. } \\
\text { variables }\end{array}$ & $\begin{array}{c}\text { Bounds } \\
\text { F-test } \\
\text { statistic }\end{array}$ & $\begin{array}{c}\text { Bounds } \\
\text { t-test }\end{array}$ & Cointegration & LM-test & JB-test & HET \\
\hline MP025 & Night & $\begin{array}{c}40,168 \\
(0,000)\end{array}$ & $\begin{array}{c}-10,967 \\
(0,000)\end{array}$ & Yes & 0,285 & 0,548 & 0,855 \\
\hline MP05 & Night & $\begin{array}{c}6,951 \\
(0,001)\end{array}$ & $\begin{array}{c}-4,485 \\
(0,001)\end{array}$ & Yes & 0,031 & 0,643 & 0,620 \\
\hline MP075 & Night & $\begin{array}{c}38,444 \\
(0,001)\end{array}$ & $\begin{array}{c}-10,725 \\
(0,000)\end{array}$ & Yes & 0,989 & 0,496 & 0,879 \\
\hline MP1 & Night & $\begin{array}{c}39,433 \\
(0,000)\end{array}$ & $\begin{array}{c}-10,849 \\
(0,000)\end{array}$ & Yes & 0,941 & 0,924 & 0,937 \\
\hline
\end{tabular}

Note: the critical values for the $F$-statistic are derived from table CI (III) (see Table 4). The range for the associated t-test is from lower-bound $\mathrm{I}(0)=-3,43$ to upper-bound $\mathrm{I}(1)=-3,82$.

Note: LM is the Lagrange multiplier test for serial correlation with a $\chi^{2}$ distribution, with only one degree of freedom; JB is the Jarque-Bera test for normality; HET is the Whitetest for heteroscedasticity with a $\chi^{2}$ distribution with only one degree of freedom.

Table 3. Critical Values for the ARDL modelling approach in relation to the Bounds test [10].

\begin{tabular}{|l|c|c|}
\hline & \multicolumn{2}{|c|}{ Case III } \\
\hline & $\mathrm{I}(0)$ & $\mathrm{I}(1)$ \\
\hline $10 \%$ critical value & 3,17 & 4,14 \\
\hline $5 \%$ critical value & 3,79 & 4,85 \\
\hline $2,5 \%$ critical value & 4,41 & 5,52 \\
\hline $1 \%$ critical value & 5,15 & 6,36 \\
\hline
\end{tabular}

\section{SHORT-RUN ESTIMATES}

Table 4 indicates the short-run implications of tourism overnight stays on the price gap, e.g. MP of wholesalers. While the EVOO price gap is found to have a lagged impact on itself in the case of 0,25 1 (one lag) and 0,5 1 (two lags), whereas in the case of the other two bottle profiles $(0,75$ and 11$)$ there is an instantaneous autoregressive short-run impact. The price gap (or MP) affects its own trajectory negatively at a statistically significant level in two cases (in a bottle: volume 0,5 1 and 11 ).

Overnight stays have a positive and statistically significant lagged impact on price gap, e.g. the MP of wholesalers, in all bottle cases except for the 0,751 case where that impact is enhanced by the instantaneous die out. One time-lagged error correction term is negative and statistically significant at a $1 \%$ level in the case of all the analysed price gaps for the various bottles.

\section{LONG-RUN ELASTICITY}

We consider weekly measurement of the included variables with 156 observations to be a sufficiently reliable basis to estimate the long-run interference of tourism overnight stays on the price gap in EVOO trading.

Table 4. Results of the short-run estimates. 


\begin{tabular}{|c|c|c|c|c|c|}
\hline \multirow{2}{*}{ Volume } & \multirow{2}{*}{ Variables } & \multicolumn{4}{|c|}{ Lags } \\
\hline & & 0 & 1 & 2 & 3 \\
\hline \multirow{3}{*}{0,251} & $\Delta \mathrm{MP}$ & - & $\begin{array}{c}-0,497 \\
(-6,899)\end{array}$ & - & - \\
\hline & $\triangle \mathrm{NOC}$ & $\begin{array}{c}0,001 \\
(0,125)\end{array}$ & $\begin{array}{c}0,097 \\
(0,846)\end{array}$ & $\begin{array}{l}0,023^{*} \\
(1,869)\end{array}$ & $\begin{array}{c}0,507 * * \\
(2,086)\end{array}$ \\
\hline & $\mathrm{ECM}_{\mathrm{t} \_1}$ & $\begin{array}{c}-0,811 * * * \\
(-7,448)\end{array}$ & - & - & - \\
\hline \multirow{3}{*}{0,51} & $\Delta \mathrm{MP}$ & & $\begin{array}{c}-0,372 * * * \\
(-3,967)\end{array}$ & $\begin{array}{c}-0,173 * * \\
(-2,312)\end{array}$ & \\
\hline & $\triangle \mathrm{NOC}$ & $\begin{array}{c}0,376 \\
(0,126)\end{array}$ & $\begin{array}{c}0,451 \\
(0,024)\end{array}$ & $\begin{array}{c}0,047 * * \\
(2,231)\end{array}$ & $\begin{array}{l}0,866^{*} \\
(1,935)\end{array}$ \\
\hline & $\mathrm{ECM}_{\mathrm{t} \_1}$ & $\begin{array}{c}-0,443 * * * \\
(-4,599)\end{array}$ & - & - & - \\
\hline \multirow{3}{*}{0,751} & $\Delta \mathrm{MP}$ & $\begin{array}{c}0,890 \\
(1,315)\end{array}$ & - & - & - \\
\hline & $\triangle \mathrm{NOC}$ & $\begin{array}{c}0,590^{* * *} \\
(2,153)\end{array}$ & $\begin{array}{c}0,887 * * \\
(2,332)\end{array}$ & $\begin{array}{c}0,342 \\
(1,276)\end{array}$ & $\begin{array}{c}-0,414 \\
(-0,743)\end{array}$ \\
\hline & $\mathrm{ECM}_{\mathrm{t} \_1}$ & $\begin{array}{c}-0,890 * * * \\
(-10,823)\end{array}$ & - & - & - \\
\hline \multirow{3}{*}{11} & $\Delta \mathrm{MP}$ & $\begin{array}{c}-0,920 \\
(-10,850)\end{array}$ & - & - & - \\
\hline & $\triangle \mathrm{NOC}$ & $\begin{array}{c}0,181 \\
(0,845)\end{array}$ & $\begin{array}{c}0,455 \\
(0,873)\end{array}$ & $\begin{array}{c}0,955 \\
(0,821)\end{array}$ & $\begin{array}{c}0,144 * * * \\
(2,561)\end{array}$ \\
\hline & $\mathrm{ECM}_{\mathrm{t} \_1}$ & $\begin{array}{c}-0,870 * * * \\
(-10,945)\end{array}$ & - & - & - \\
\hline
\end{tabular}

significant at level $1 \%$,

*** significant at the level $5 \%$

*** significant at the level $10 \%$

The long-run elasticity of a single independent variable (NIGHT) with respect to the dependent variable (MP) is shown in Table 4. All EVOO price gaps referring to various sold bottles have statistically significant and positive relationships, and are affected by an increase in international tourism overnight stays. Here, as predicted in the theoretical overview, we can state that tourism demand causes a price gap/MP increase for wholesalers.

Table 5. Long-run estimates of dependent variable MP.

\begin{tabular}{|c|c|c|c|c|}
\hline Variables & $\mathbf{0 , 2 5}$ I volume & $\mathbf{0 , 5}$ I volume & $\mathbf{0 , 7 5}$ I volume & 1 I volume \\
\hline \multirow{2}{*}{ NOC } & $0,76^{* *}$ & $0,756^{* *}$ & $0,329 * * *$ & $0,412^{*}$ \\
& $(2,311)$ & $(2,231)$ & $(2,897)$ & $(2,119)$ \\
\hline \multirow{2}{*}{ intercept } & 2,447 & 1,296 & 1,185 & 1,826 \\
& $(1,452)$ & $(1,397)$ & $(1,264)$ & $(1,003)$ \\
\hline
\end{tabular}

significant at level $1 \%$,

${ }^{* *}$ significant at the level $5 \%$

${ }^{* * *}$ significant at the level $10 \%$

\section{TODA-YAMAMOTO CAUSALITY TEST}

After estimating long-run results, we proceeded to the causality test. However, first the longrun causality is conducted by the coefficient t-statistics, which stand before the ETCt-1, wherein this term measures how fast the deviations from the long-run equilibrium die out 
following changes in the NIGHT variable. The lagged ECT coefficients from Table 5(4) show that international overnight stays and MP in all types of contracted bottled EVOO were restored to the long-run equilibrium. The analysis of Equation (6), as presented in Table 7, indicates that there is long-run cointegration among the variables at the $1 \%$ significance level; moreover, the ECT coefficients revealed in Table 8 imply that any deviation from the long-run equilibrium is corrected within the adjustment speed range of 44-89\% (the quickest speed is measured for the 0,751 volume EVOO bottle). This also indicates a strong causality for the tourist demand variable on the MP of EVOO wholesalers.

From the estimation of the Toda-Yamamoto Granger causality test (see Table 5), we can make the following assertion based on the results of this study:

For 0,75 1 and 11 bottled EVOO there is unidirectional causality flowing from international overnight stays demand to the price gap (MP), thereby supporting our hypothesis that tourism affects MP in EVOO trading. For the 0,25 volume bottle, the reverse causality evidence, where tourism overnight stays is caused by price gap, revealed that the MP also has side-effects on tourism overnights, thus forming a bidirectional causality linkage.

Table 6. Toda-Yamamoto no-causality test two-variate VAR model results.

\begin{tabular}{|c|c|c|c|c|l|}
\hline $\begin{array}{c}\text { EVOO } \\
\text { volume }\end{array}$ & Lag(k) & Lag (k+dmax) & Chi- sq & Prob. & Direction of causality \\
\hline \multirow{2}{*}{0,251} & 1 & $1+2$ & 5,654 & $0,098^{*}$ & NIGHT $\rightarrow$ MP \\
\cline { 2 - 6 } & 1 & $1+2$ & 13,455 & $0,018^{* *}$ & MP $\rightarrow$ NIGHT \\
\hline \multirow{2}{*}{0,51} & 1 & $1+2$ & 2,756 & 0,446 & NIGHT do not cause MP \\
\cline { 2 - 6 } & 1 & $1+2$ & 9,966 & 0,813 & MP do not cause NIGHT \\
\hline \multirow{2}{*}{0,751} & 1 & $1+2$ & 12,734 & $0,013^{* *}$ & NIGHT $\rightarrow$ MP \\
\cline { 2 - 6 } & 1 & $1+2$ & 0,814 & 0,556 & MP do not cause NIGHT \\
\hline \multirow{2}{*}{11} & 1 & $1+2$ & 9,388 & $0,024^{* *}$ & NIGHT $\rightarrow$ MP \\
\cline { 2 - 6 } & 1 & $1+2$ & 0,896 & 0,403 & MP do not cause NIGHT \\
\hline
\end{tabular}

Note: k+dmax denotes VAR order. The lag length selection was based on AIC: Akaike information criterion.

"significant at level $1 \%$,

***ignificant at the level $5 \%$

*** significant at the level $10 \%$

$\rightarrow$ one-way causality

\section{CONCLUSIONS AND POLICY IMPLICATIONS}

This article was directed towards attaining a full understanding of the causal relationships between international tourism overnight stays and the MP of EVOO from the wholesaler's perspective. For the bottled EVOO products that pass the rigorous statistical testing - the unit root, cointegration, and bounds testing [10], Toda-Yamamoto causality analysis was also particularly important.

Having applied the ADF (Augmented Dickey-Fuller) and DF-GLS (Elliott, Rothenberg, and Stock) unit root tests, we found that the variables are a mix of I(0) and I(1). Hence, the ARDL bounds test approach of cointegration has been employed followed by the Toda- Yamamoto Granger causality test in order to shed more light on the relationship between international tourism stays and the MP of wholesaler agent proxies by price gap. The positive empirical evidence about cointegration is acquired from ARDL bounds test and research proceeded by investigating facts about the short-run and long-run relationship, as well as the ECM based strong causality test and finally the Toda-Yamamoto Granger causality test. The results from the ARDL 
approach demonstrate that, regardless of which volume has been purchased, EVOO reveals cointegration, which is manifested in the assumed link between the MP and tourist demand.

There is significant statistical evidence that tourist demand has swelled in recent year, and that international tourism overnight stays have had a positive impact on the MP growth of EVOO in both the short-run and the long-run.

For larger bottles $(0,75$ and 1 1), there is unidirectional causality flowing from tourism consumption, which we supposed originated from the NIGHT variable, to the artificially constructed MP variable. This fact supports our thesis that tourism growth impact elevates the MP of wholesalers thanks to the product discussed within this article. The feedback hypothesis discovered here has been found to be relevant in the case of 0,251 . In this case a bidirectional causality unfolded. In addition, 0,5 1 bottled EVOO does not manifest any side-effect relationship at all, at least when this issue was assessed via Toda- Yamamoto causality testing.

Our insights are invaluable for the implementation of any relevant tax policy measures/instruments with the objectives of advancing either non-board consumption or augmenting the consumer surplus regarding EVOO purchases, presupposing the desire to pursue olive style tourism. The consumers, in particular foreign tourists, are not very knowledgeable; put bluntly, they are myopic regarding the attributes of EVOO and may misperceive the price as a proxy for quality. Our empirical results also suggest the following implications that public policy must touch on. The Croatian executive authorities should encourage a policy of reducing agrarian import dependence in general and support the production of EVOO in Croatia. The EVOO stored by wholesalers should be controlled and organoleptic properties should be analysed in order to eliminate the information white noise throughout the rest of the supply chain. Since the final consumers for these smaller or larger bottles of oil are predominantly tourists, the goal must be that foreign tourists have a better feeling about the price-quality ratio. That policy may reduce the MP trading with the EVOO within Croatia despite the tourist demand, which will perpetuate the same phenomenon on a nationwide scale.

There are certain limitations of this study. This study was focused on measuring wholesalers' market power. However, they are only one stakeholder in the observed supply chain. Therefore, we propose guidelines for further research in this insufficiently researched topic along with the line questioning how tourism demand impact MP of EVOO. The next research could examine other stakeholders in the olive oil supply chain in Croatia (marketing agency, transport, the state). Direct channels, the packaging cost, the processing subventions that boost supply, were not included in the research and they might be incorporated for future research. Although Croatia, as well as other Mediterranean countries, has a long olive oil production tradition, the production of olive oil in Croatia almost doubled in the last 20 years. Consequently, olive production surfaces have increased from 11,398 ha in 2000 to 18.606 ha in 2019 followed by an increase in olive oil production volume (from 28,188 hl in 2000 to $44,497 \mathrm{hl}$ in 2019) [42]. In a future study, somehow detached from our central topic, it could be investigated, by the quasi-experimental method of difference-in-difference regression how the input of state subsidies affected the growth of olive oil production.

\section{ACKNOWLEDGEMENT}

This article is a result of scientific project Tourism development and destination impacts supported by the Faculty of Economics and Tourism 'Dr. Mijo Mirković', Juraj Dobrila University of Pula. Any opinions, findings, and conclusions or recommendations expressed in this article are those of the author(s) and do not necessarily reflect the views of the Faculty of Economics and Tourism 'Dr. Mijo Mirković' Pula. 


\section{APPENDIX}
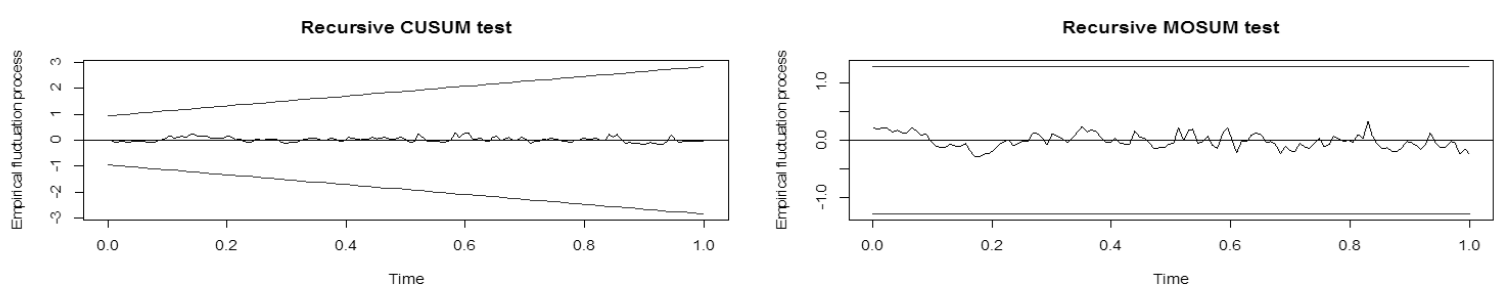

Figure 1. Plot of CUSUM and MOSUM: case of MP025.
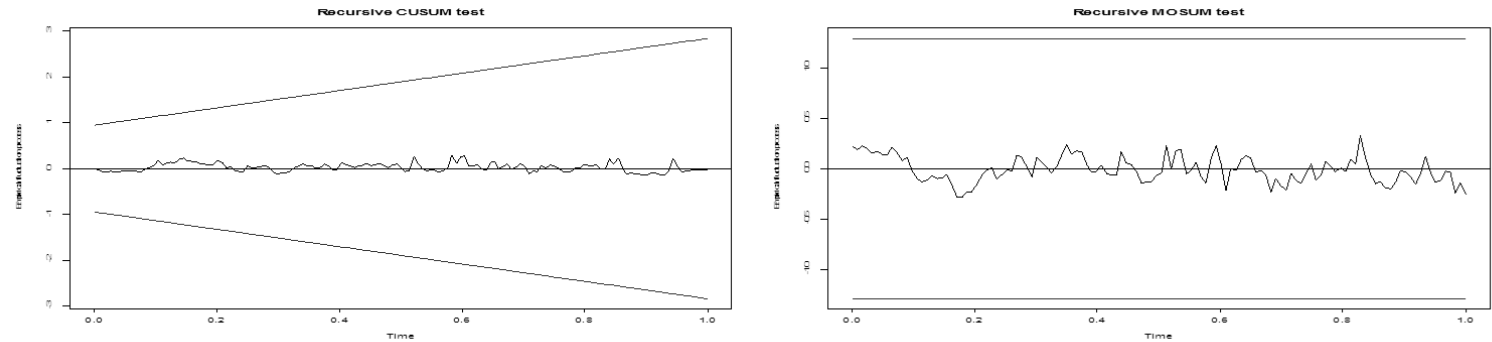

Figure 2. Plot of CUSUM and MOSUM: case of MP05.
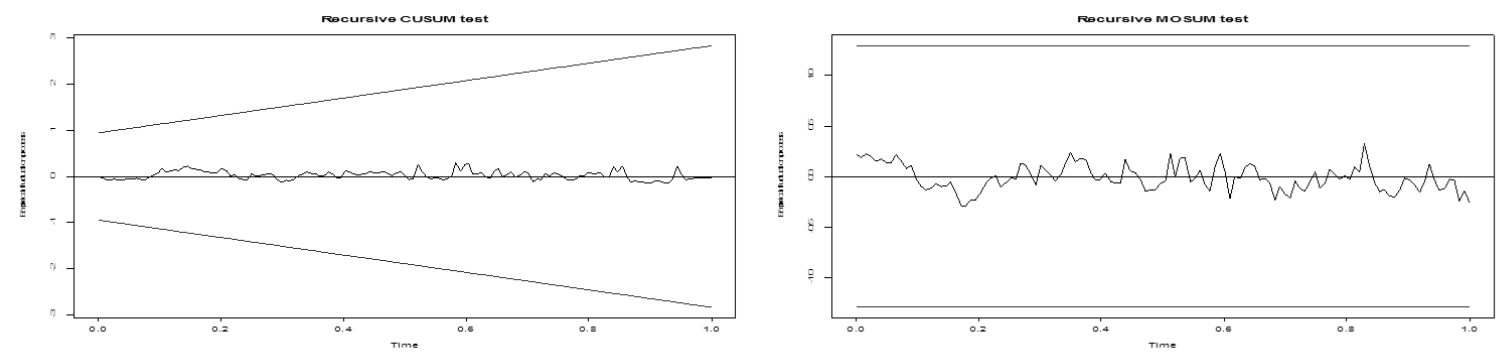

Figure 3. Plot of CUSUM and MOSUM: case of MP075.
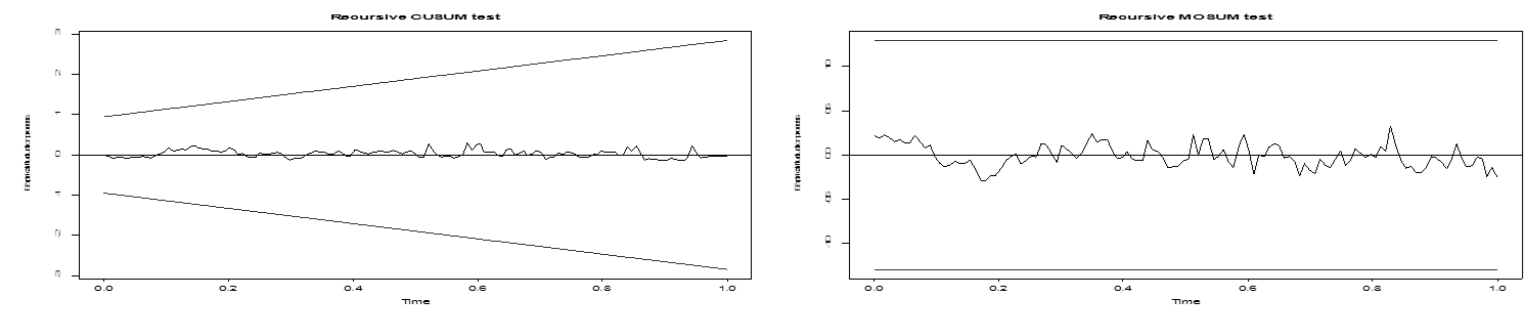

Figure 4. Plot of CUSUM and MOSUM: case of MP1.

\section{REFERENCES}

[1] Ali, S.B.; Selmi, S. and Hellali, W.: Market power of Tunisian olive oil in EU market. EuroMed Journal of Management 2(3), 230-239, 2018, http://dx.doi.org/10.1504/EMJM.2018.10014465,

[2] Tasdogan, C.; Tsakiridou, E. and Mattas, K.: Country market power in EU olive oil trade. South-Eastern Europe Journal of Economics 2(3), 211-219, 2005,

[3] Broos, E., et al.: EU Wholesale Trade: Analysis of the Sector and Value Chains. The Vienna Institute for International Economic Studies, wiiw Research Reports 415, 2016,

[4] Ganapati, S.: Growing Oligopolies, Prices, Output, and Productivity.

Center for Economic Studies, U.S. Census Bureau, Working Papers 18-48, 2018, 
[5] Sheldon, I.M.: The competitiveness of agricultural product and input markets: A review and synthesis of recent research.

Journal of agricultural and applied economics 49(1), 1-44, 2017, http://dx.doi.org/10.1017/aae.2016.29,

[6] Filipović, F.: Quality of foreign from the shelves and Croatian olive oil. In Croatian. http://www.niranaliza.hr/kvaliteta-stranog-s-polica-i-hrvatskog-maslinovog-ulja/blog,

[7] Suhartanto, D.; Dean, D.; Sosianika, A. and Suhaeni, T.: Food souvenirs and their influence on tourist satisfaction and behavioural intentions.

European Journal of Tourism Research 18, 133-145, 2018,

http://dx.doi.org/10.54055/ejtr.v18i.317,

[8] Romo-Muñoz, R.A., et al.: Heterogeneity and nonlinearity in consumers' preferences: An application to the olive oil shopping behavior in Chile.

PLoS ONE 12(9), 1-13, 2017,

[9] Pesaran, H.M. and Shin, Y.: An autoregressive distributed lag modelling approach to cointegration analysis.

In: Storm, S., ed.: Econometrics and Economic Theory in the 20 $0^{\text {th }}$ Century: The Ragnar Frisch Centennial Symposium. Econometric Society Monographs. Cambridge University Press, Cambridge, pp.371-413, 1999,

[10]Pesaran, M.H.; Shin, Y. and Smith, R.J.: Bounds testing approaches to the analysis of level relationships.

Journal of Applied Econometrics 16(3), 289-326, 2001, http://dx.doi.org/10.1002/jae.616,

[11]Toda, H.Y. and Yamamoto, T.: Statistical inference in Vector Autoregressions with possibly integrated processes.

Journal of Econometrics 66(1-2), 225-250, 1995,

http://dx.doi.org/10.1016/0304-4076(94)01616-8,

[12] Goldberg, P.K. and Knetter, M.M.: Goods Prices and Exchange Rates: What Have We Learned?

Journal of Economic Literature 35(3), 1243-1272, 1997,

[13]Folgado-Fernández, J.A.; Campón-Cerro, A.M. and Hernández-Mogollón, J.M.:

Potential of olive oil tourism in promoting local quality food products: A case study of the region of Extremadura, Spain.

Heliyon 5(10), 26-53, 2019,

[14]Hernández-Mogollón, J.M.; Di-Clemente, E.: Folgado-Fernández, J.A. and CampónCerro, A.M.: Olive oil tourism: state of the art.

Tourism and hospitality management 25(1), 179-207, 2019, http://dx.doi.org/10.20867/thm.25.1.5,

[15] López-Guzmán, T.; Cañero, P.; Moral-Cuadra, S. and Orgaz, F.: An exploratory study of olive tourism consumers.

Tourism and Hospitality Management 22(1), 57-68, 2016, http://dx.doi.org/10.20867/thm.22.1.1,

[16] Orgaz, F.; Moral, S.; López-Guzmán, T. and Cañero, P.: Study of the existing demand in the field of oleotourism. Andalusia's house. In Spanish.

Cuadernos de Turismo 39, 437-453, 2017,

[17] Calzati, V. and De Salvo, P.: The roll of gastronomic events in the promotion and valorization of rural areas. The house of Frantoi opened in Umbria. In Italian. FrancoAngeli, Milano, 2017,

[18] Moral-Cuadra, S.; López-Guzmán, T.; Orgáz, F. and Cañero, P.: Motivation and satisfaction of the oleos of tourists in Spain. Andalusia's house. In Spanish. Espacios 38(58), 4-17, 2017,

[19] Millán, M.G.; del Populo, M. and Sánchez-Rivas, J.: Oleotourism as a Sustainable Product: An Analysis of Its Demand in the South of Spain (Andalusia).

Sustainability 10(101), 1-19, 2018, http://dx.doi.org/10.3390/su10010101, 
[20] D'Adamo, I.; Falcone, P.M.; Gastaldi, M. and Morone, P.: A Social Analysis of the Olive Oil Sector: The Role of Family Business.

Resources 8(3), No. 151, 2019,

http://dx.doi.org/10.3390/resources8030151,

[21]Bimbo, F.; Roselli, L.; Carlucci, D. and de Gennaro, B.C.: Consumer Misuse of Countryof-Origin Label: Insights from the Italian Extra-Virgin Olive Oil Market.

Nutrients 12(7), 21-50, 2020, http://dx.doi.org/10.3390/nu12072150,

[22] Yan, J., et al: Food fraud: Assessing fraud vulnerability in the extra virgin olive oil supply chain.

Food Control 111, 1-10, 2020,

[23]Ballco, P. and Gracia, A.: Do market prices correspond with consumer demands? Combining market valuation and consumer utility for extra virgin olive oil quality attributes in a traditional producing country.

Journal of Retailing and Consumer Services 53, No. 101999, 2020,

http://dx.doi.org/10.1016/j.jretconser.2019.101999

[24] Hong, H. and Shum, M.: Using Price Distributions to Estimate Search Costs.

The RAND Journal of Economics 37(2), 257-275, 2006, http://dx.doi.org/10.1111/j.1756-2171.2006.tb00015.x,

[25] Hernández, J.M.; Folgado, J.A. and Campón, A.M.: Oleotourism in the Sierra de Gata and Las Hurdes (Cáceres): Analysis of the potential of a test of a product. In Spanish. International Journal of Scientific Management and Tourism 1(2), 333-354, 2016,

[26]López-Guzmán, T.; Cañero, P.; Moral, S. and Orgaz, F.: An exploratory study of olive tourism consumers.

Tourism and Hospitality Management 22(1), 57-68, 2016,

http://dx.doi.org/10.20867/thm.22.1.1,

[27] Sánchez, J.D. and Ortega, A.: The Olivarian Olive Cultivation: Historical Conformation, Patriotic Values and Cultural-Tourist Projection. In Spanish.

Cuadernos de Turismo 37, 377-402, 2016, http://dx.doi.org/10.6018/turismo.37.256281,

[28] Shy, Oz: Industrial Organization, Theory and Applications.

The MIT Press, Cambridge, 1995,

[29] Vollrath, D.: Fully Grown: Why a Stagnant Economy is a Sign of Success.

University of Chicago Press, Chicago, 2020,

[30]Brown, R.L.; Durbin, J. and Evans, J.M.: Techniques for testing the constancy of regression relationships over time.

Journal of the Royal Statistical Society 37(2), 149-192, 1975,

http://dx.doi.org/10.1111/j.2517-6161.1975.tb01532.x,

[31] Pesaran, M.H. and Pesaran, B.: Working with Microfit 4.0: Interactive econometric analysis. Oxford University Press, Oxford, 1997,

[32] Zapata, H.O. and Rambaldi, A.N.: Monto Carlo evidence on cointegration and causation. Oxford Bulletin of Economics and Statistics 59(2), 285-298, 1997, http://dx.doi.org/10.1111/1468-0084.00065,

[33] Wolde-Rufael, Y.: Disaggregated industrial energy consumption and GDP: the case of Shanghai, 1952-1999.

Energy Economics 26(1), 69-75, 2004, http://dx.doi.org/10.1016/S0140-9883(03)00032-X,

[34] Wolde-Rufael, Y.: Energy Demand and Economic Growth. Journal of Policy Modeling 27(8), 891-903, 2005, http://dx.doi.org/10.1016/j.jpolmod.2005.06.003,

[35] Mavrotas, G. and Kelly, R.: Old wine in new bottles: Testing causality between savings and growth.

The Manchester School 69, 97-105, 2001,

http://dx.doi.org/10.1111/1467-9957.69.s1.6, 
[36]-: Agricultural Market Information System.

http://www.amis-outlook.org,

[37] Eurostat: Nights spent at tourist accommodation establishments (tour_occ_nim). http://ec.europa.eu/eurostat,

[38] Sax C. and Steiner, P.: Temporal Disaggregation of Time Series.

The R Journal 5(2), 80-87, 2013, http://dx.doi.org/10.32614/RJ-2013-028,

[39] Narayan, P.K.: The saving and investment nexus for China: evidence from cointegration tests 1979-1990.

Applied Economics 37(17), 2005, http://dx.doi.org/10.1080/00036840500278103,

[40] Ang, J.B.: Are saving and investment cointegrated? The case of Malaysia (1965-2003). Applied Economics 39(17), 2167-2174, 2017,

[41] Elliott, G.; Rothenberg, T.J. and Stock, J.H.: Efficient Tests for an Autoregressive Unit Root. Econometrica 64(4), 813-836, 1996, http://dx.doi.org/10.2307/2171846,

[42] Rebić, M. and Hoppe, I.: Market information system in agriculture. In Croatian. http://www.tisup.mps.hr. 